\title{
COMPLEMENTARY AND INNOVATIVE METHOD IN GENITAL HPV TESTING FOR CERVICAL CANCER PREVENTION
}

\author{
GEORGETA GÎNFĂLEAN ${ }^{1}$ \\ 1 “Lucian Blaga” University of Sibiu
}

Keywords: genital HPV infection, early detection methods, cervical cancer, early diagnosis, optimal screening, healing of cervical lesions, reproductive prognosis, chronic genital HPV infection, primary prevention, secondary prevention, co-tests, selfharvesting test

\begin{abstract}
Considering actual SARS-COV 2 pandemic, the comfort and time of the female patient' trend is to minimize the time spent in the doctor's office, so that auto-testing is a solving problem in this context. This paper aims at the importance of self-collected urine and vaginal samples, since actual studies are showing that is a complementary method in HPV-testing and a screening method for prevention of cervical cancer. Genital HPV infection is responsible for approximately $99 \%$ of cervical cancers, and is considered a sexually transmitted disease. Given that eight out of ten patients have at least one episode of HPV infection in their lifetime, there is a need for a method of early detection of genital HPV infection. Cervical cancer is the second type of diagnosed cancer in the rank of genital cancers and the third leading cause of cancer death among the female population. In Romania, the frequency of cervical cancer and mortality caused by this type of cancer remains high. In 2018 Globocan, it was mentioned that the occurrence of cervical cancer in Romania was 8.6\%, and the mortality was 19.5/10,000 women. Worldwide, the following have been implemented: primary prevention programmes (via immunization) and secondary prevention programmes - traditional cytological testing, to which co-tests have been added. In the co-testing sector, there has been found with an updated visa-the self-harvesting test, being considered a complementary and innovative method in genital HPV testing, which aims to: identify the presence of highly oncogenic HPV strains with a marked sensitivity. Self-harvesting testing aims to: signal the presence of highly oncogenic strains, extrapolation can lead to early identification of the number of cases of precancerous lesions of the cervix and implicitly of cervical cancer.
\end{abstract}

Cervical cancer is the second type of cancer diagnosed in the rank of genital cancers and the third leading cause of cancer deaths among the female population.(1) According to the World Health Organization (WHO), 50,000 women with cervical cancer are diagnosed each year, of whom 200,000 die from this disease. $(2,3)$

Cervical cancer is considered a major public health problem, given that approximately $90 \%$ of deaths from this neoplasm occur in developing countries, with a clear geographical variation between developed and developing countries.

The variation is explained by the presence of three elements common to developing countries: the increased prevalence of Human Papilloma Virus (HPV) infections, due to a liberal attitude towards sexual practices (HPV infection being included in sexually transmitted diseases) and the lack of implementation, reduced accessibility or inefficient screening programme (diagnosis, therapeutic sanction and suboptimal follow-up of precancerous cervical lesions).

In Romania, the frequency of cervical cancer and mortality caused by this type of cancer continues to increase, there were 3308 new diagnosed cases, of which according to statistics 1743 females died. In 2018, Globocan mentioned that the occurrence of cervical cancer in Romania was $8.6 \%$, and the mortality $19.5 / 100,000$ women.(4)

Genital HPV infection is responsible for approximately $99 \%$ of cervical cancer cases, respectively of neoplastic precursor lesions, which is considered a sexually transmitted disease. Given that eight out of ten patients have at least one episode of HPV infection in their lifetime, a method of early genital HPV infection method is in need. Thus, we increase the number of cases diagnosed early, which can be included in a complex bimodal therapeutic plan according to the degree of severity - optimal medical and surgical treatment, which will lead to healing of cervical lesions, which in terms will maintain the women's reproductive prognosis during their reproductive age, where we face the highest incidence of chronic genital HPV infection.

Figure no. 1. Globocan 2018, number of new cases of cancers diagnosed in the female population of Romania (3)

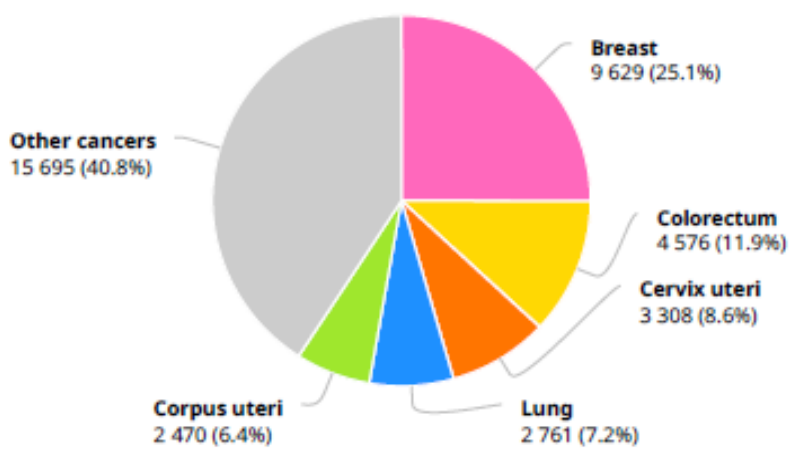

${ }^{1}$ Corresponding author: Gânfălean Georgeta, Str. Moreni, Nr. 19, Sibiu, România, E-mail: ginfalean.georgeta@yahoo.com, Phone: +40723 254897 Article received on 19.08.2020 and accepted for publication on 02.12 .2020 
CLINICAL ASPECTS

Figure no. 2. Globocan 2018, frequency ratio to mortality rate, in the female population in Romania (3)

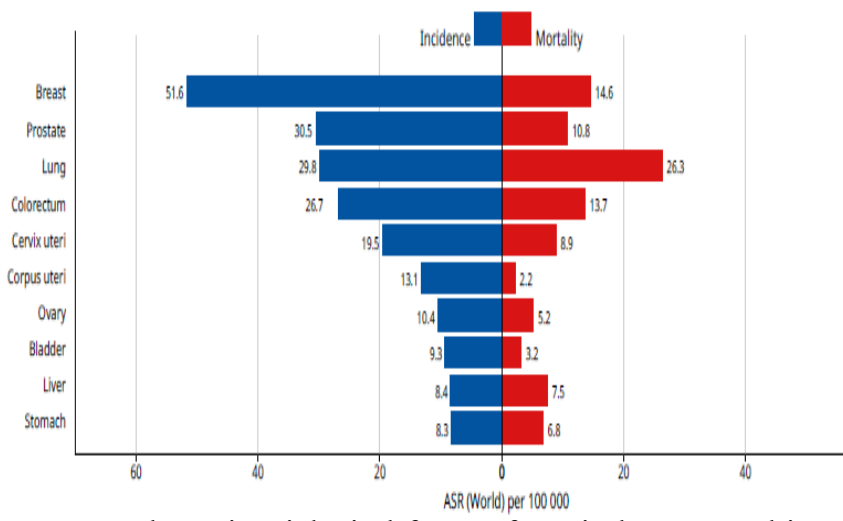

The main etiological factor of cervical cancer and its precursors is the persistent infection with high-risk strains of Human Papilloma Virus (HPV).

Virology and molecular biology studies have shown that, of this $99 \%$ of HPV infections, $80 \%$ are transient (mainly in the female population aged 24 , adolescents) and the rest are persistent (especially within oncogenic strains of type 16 and 18 , out of all 14 oncogenic strains).

According to the theory of lesion continuity in regards to dysplastic lesion's neoplasia, especially in the female population aged 30 years and over, which due to the accumulation of genomic alterations in somatic cells (representing primum movens in the process of tumorigenesis) make them more susceptible to infection or malignant transformation. $(5,6)$

On a global scale, the following have been implemented: primary prevention programmes (via HPV vaccination, immunization) and secondary prevention - cervical cytology screening in a classical or liquid manner to which cotests have been added - primary HPV phenotyping and Immunocytochemical detection of biomarkers from cytology and biopsies obtained during colposcopy, direct biopsy of a suspicious lesion or on the pieces obtained following the application of surgical treatment.

In the co-testing sector, with an updated aim- the selfharvesting test with urine or genital samples, being considered a complementary and innovative method in genital HPV testing. The self-harvesting test (Easy HPV Test, Neumann Labs; INNO-LiPA HPV Genotyping, Fujirebio; Cobas 4800, Roche) directly, by the patient at home, aims to: identify the presence of highly oncogenic HPV strains with significant sensitivity, cited in specialized articles close of $100 \% .(7,8)$ The highly oncogenic HPV strains, identified when the self-collection sample is taken (genitally, urinary), are: 16, 18, 31, 33, 45, 52, 58, 35, 39, 51, $56,59,66$ and 68. $(9,10)$

This self-harvesting test aims at: a better identification of the number of cases of precancerous lesions of the cervix and implicitly of the cervical cancer, by signaling the presence of highly oncogenic strains, respectively an early identification and early diagnosis of patients affected by this disease. A positive result of the self-collected sample by the patients offers them an alarm signal regarding the rhythm of the consultation and the performance of secondary tests with a role in prevention - the Babes-Papanicolau cytology test.

Self-testing for primary HPV testing is considered a reliable method for the detection of stage $2+$ intraepithelial cervical neoplasia (CIN 2+), according to Polman et. Al. Lancet Oncol 2019. Although the procedure has a low sensitivity to tests collected in a medical environment, the detection rate of CIN 2+ was $29.4 \%$, cases that were additionally reassessed colposcopically, thus avoiding congestion in the medical environment, amid the COVID-19 pandemic.

This type of test is done by the patient herself, along with other types cervical cancer secondary preventions that were mentioned in a study conducted 5 years ago and then published in the International Journal of Cancer, with a considerable result of self-harvesting, similar to HPV-DNA investigations and traditional cytological testing.(11)

The new trends in cervical screening, with cost effectiveness analysis criteria, tend to change the methodology of testing, from classical cytological method, to testing HPVhighly oncogenic strains. According to a study conducted in the Netherlands (women aged $=>30$ years unvaccinated against HPV were co-opted in the study), in 2017, which aimed to: compare cost-effectiveness between the classic cytology program and the HPV strain detection program Highly oncogenic (HPC-hr), it is considered opportune to change the optics in favor of the viral detection of HPV -hr strains. The new cervical cancer screening program, proposed by the Dutch study, decreased mortality rate by $4 \%$ and incidence by $1 \%$ compared to the classic cytology program. Secondary colposcopic assessments without precancerous lesions or in case of CIN $2+$ or higher grade increased by $172 \%$, but also increased age-adjusted quality of life $13 \%$. Total costs through the new PHV - hr strain detection program reduced costs by $21 \%$. Through all these arguments they established in the study that the determination of HPV $-\mathrm{hr}$ has all the necessary attributes in terms of cost- effectiveness to sensitive testing. (table no. 1).(12)

Table no. 1. Differences in cost effectiveness between the classic cervical screening program -HPV strains-hr

\begin{tabular}{|c|c|c|c|c|}
\hline & \multicolumn{3}{|c|}{ Screen strategy } & \multirow{2}{*}{$\begin{array}{c}\text { Difference between } \\
\text { hrHPV and cytology (\%) }\end{array}$} \\
\hline & No screening & Cytology & hrHPV & \\
\hline \multicolumn{5}{|l|}{ Effects (numbers, undiscounted) } \\
\hline Total screening tests & - & 444356 & 364306 & -18 \\
\hline Primay screening tests (GP) & - & 422959 & 281710 & -33 \\
\hline Primay selt-samples & - & - & 25797 & NA \\
\hline Reflex cytology after positive GP test & - & - & 33906 & NA \\
\hline Cytology smear a atter postive selt-sample & - & - & 3384 & NA \\
\hline Tests 6 or 18 months atter primary test & - & 21397 & 19509 & -9 \\
\hline Referrals to colposcopy & - & 746 & 12841 & +66 \\
\hline No lesion present & - & 1458 & 5242 & +260 \\
\hline CN 1 & - & 1514 & 2851 & +88 \\
\hline CN 2 & - & 1523 & 2039 & +34 \\
\hline CN 3/AIS & - & 3070 & 2509 & -18 \\
\hline Screen detected cervical cancer & - & 181 & 200 & +10 \\
\hline Clinically detected cervical cancers & 1157 & 522 & 496 & -5 \\
\hline Total cervical cancers & 1157 & 704 & 697 & -1 \\
\hline Cervical cancer mortality & 440 & 215 & 206 & -4 \\
\hline Life years gained compred to no screening & - & 5163 & 5250 & +2 \\
\hline QALY's gained compared to no screening & - & 4580 & 5161 & +13 \\
\hline \multicolumn{5}{|l|}{ Costs (€ millions, undiscounted) } \\
\hline Screening tests & - & 33 & 19 & -41 \\
\hline Diagnosis and treatment of precancerous lesions and fase-positive referrals & - & 9 & 12 & +24 \\
\hline Diagnosis and treatment of cervical cancer & 14.7 & 8 & 8 & -2 \\
\hline 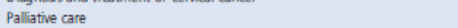 & 13.1 & 6 & 6 & -4 \\
\hline 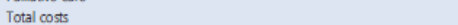 & 27.7 & 57 & 45 & -21 \\
\hline \multicolumn{5}{|l|}{ Costeffectiveness (in $€$, discounted yearly by $3 \%$ for both costs and effects) } \\
\hline Cots per life year ganed compred to no screening & - & 15,247 & 10,890 & -29 \\
\hline Costs per QALY gained compared to no screening & - & 22,678 & 12,225 & -46 \\
\hline
\end{tabular}

In 2018 The Preventive Services Task Force (USPSTF) launched a final guide on cervical cancer screening, based on the previously discussed premises. The USPSTF recommends the following screening algorithms, except for patients with "uterine" exposure to diethylsibestrol or patients with compromised immune status (HIV):

Grade A recommendations for women aged 21-65:

Between 21-29 years: cervical cytological screening once every 3 years;

$>$ Between 30-65 years: cytological cervical screening once every 3 years, single or co-testing once every 5 years HPVhr.

Grade D recommendations (regardless of sexual 


\section{CLINICAL ASPECTS}

history or immune status via vaccination) for:

$>$ Women under $<21$ years old are not recommended screening (HPV infections with high rate of getting rid of the virus).

$>$ Women over $>65$ years: only in the absence of a previous test or if they have an increased risk for cervical cancer.

$>$ In the context of post-hysterectomy status" only in the context of high-grade precancerous cervical lesions (CIN 2 , CIN3) or cervical cancer.(13)

We concluded with the argument by the American Cancer Society (ACS), which recommends that primary HPV testing begin at age of 25 every 5 years.(14)

\section{REFERENCES}

1. Marth C, Landoni F, Mahner S, McCormack M, GonzalezMartin A, Colombo N, on behalf of the ESMO Guidelines Committee, Cervical Cancer : ESMO Clinical Practice Guideline for diagnosis, treatment and follow-up, Annals of Oncology. 2017;28(Suppl 4):iv72-iv 83.

2. SM Group, Immunohistochemistry in Cervical Cancer, Cervical Cancer: Recent Reserch and Review Studies; www.smgebooks.com. Accessed on 10.08.2020.

3. Ginfalean G. Surgical therapeutic methods in cervical cancer - "Lucian Blaga" University of Sibiu Publishing House, ISBN 978-606-12-1356-6; 2016.

4. Globocan 2018 https://gco.iarc.fr/today/data/factsheets/populations/642romania-fact-sheets.pdf. Accessed on 12.09.2020.

5. Gînfălean G. Improving cytological screening. New Additional Methods of co-testing. Acta Medica Transilvanica. 2018;23(2):69-71.

6. Morar S, Cernuşcă-Miţariu M, Burlibaşa M, Cipăian C, Chicea L, Popa M, Ștef L, Pumnea M, Ginfalean G. Early diagnosis of cervical cancer - Detection methods in tendencies and progress in sibian medicine- Volume VII Lucian Blaga University Publishing House in Sibiu ISBN 978-606-12-1395-5; 2016.

7. Gheorghe L. Easy HPV Test - depistare a virusului HPV, autorecoltarea probelor la domiciliu; https://raportuldegarda.ro/articol/easy-hpv-test-screening. Accessed on 14.07.2020.

8. Fujirebio, INNO-LiPA HPV Genotyping https://www.fujirebio.com/en/products-solutions/innoliparhpv-genotyping-extra-ii. Accessed on 10.08.2020.

9. Cui M, Chan N, Liu M, Thai K, Malaczynska J, Singh I, Zhang D, Ye F. Clinical performance of Roche Cobas 4800 HPV Test. J Clin Microbiol. 2014 Jun;52(6):2210-1.

10. Morar S, Cernuşcă-Miţariu M, Burlibaşa M, Cipăian C, Chicea L, Popa M, Ștef L, Pumnea M, author Ginfalean G. The role of HPV infection in cervical ocogenesis in tendencies and progress in sibian medicine - Volume VII "Lucian Blaga" University of Sibiu Publishing House ISBN 978-606-12-1395-5; 2016.

11. Denton KJ. Cervical self- sampling yields useful cytology, International Journal of Obstetrics \& Gynaecology. 2020;127(13).

12. Jansen E, Naber SK, Aitken CA, de Koning HJ, van Ballegooijen M, de Kok I. Cost-effectiveness of HPVbased cervical screening based on first year results in the Netherlands: a modelling study. BJOG; 2020.

13. Cervical Cancer Screening Guidelines - Including 'HPV Only' Option, https://www.obgproject.com/2017/09/12/uspstf-releasesdraft-guidelines-cervical-cancer-screening-end-co-testing/. Accessed on 14.07.2020.

14. Harrison P. HPV Test Is Preferred Method for Cervical Cancer Screening: ACS, Medscape Medical News, 2020, https://www.medscape.com/viewarticle/935126? $\mathrm{src}=\mathrm{soc} \mathrm{fb}$ 200807_mscpedt_news_mdscp_acs\&faf $=1$. Accessed on $\overline{13} .08 .20 \overline{2} 0$. 